\title{
Primary Ciliary Dyskinesia Due to Microtubular Defects is Associated with Worse Lung Clearance Index
}

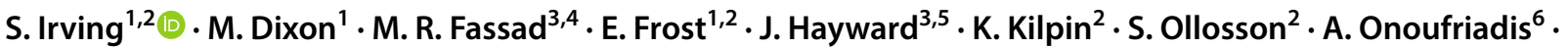



Received: 7 September 2017 / Accepted: 4 January 2018 / Published online: 24 January 2018

(c) The Author(s) 2018. This article is an open access publication

\begin{abstract}
Purpose Primary ciliary dyskinesia (PCD) is characterised by repeated upper and lower respiratory tract infections, neutrophilic airway inflammation and obstructive airway disease. Different ultrastructural ciliary defects may affect lung function decline to different degrees. Lung clearance index (LCI) is a marker of ventilation inhomogeneity that is raised in some but not all patients with PCD. We hypothesised that PCD patients with microtubular defects would have worse (higher) LCI than other PCD patients.

Methods Spirometry and LCI were measured in 69 stable patients with PCD. Age at testing, age at diagnosis, ethnicity, ciliary ultrastructure, genetic screening result and any growth of Pseudomonas aeruginosa was recorded.

Results Lung clearance index was more abnormal in PCD patients with microtubular defects (median 10.24) than those with dynein arm defects (median 8.3, $p=0.004$ ) or normal ultrastructure (median 7.63, $p=0.0004$ ). Age is correlated with LCI, with older patients having worse LCI values $(p=0.03, r=0.3)$.

Conclusion This study shows that cilia microtubular defects are associated with worse LCI in PCD than dynein arm defects or normal ultrastructure. The patient's age at testing is also associated with a higher LCI. Patients at greater risk of obstructive lung disease should be considered for more aggressive management. Differences between patient groups may potentially open avenues for novel treatments.
\end{abstract}

Keywords Lung function $\cdot$ Paediatrics $\cdot$ Rare disease $\cdot$ Ciliopathy

Electronic supplementary material The online version of this article (https://doi.org/10.1007/s00408-018-0086-x) contains supplementary material, which is available to authorized users.

S. Irving

s.irving@ rbht.nhs.uk

1 National Heart and Lung Institute, Imperial College London, London, UK

2 Royal Brompton \& Harefield NHS Trust, Sydney Street, London SW3 6NP, UK

3 Genetics and Genomic Medicine, University College London (UCL) Great Ormond Street Institute of Child Health, London, UK

4 Human Genetics Department, Medical Research Institute, Alexandria University, Alexandria, Egypt

\section{Introduction}

Primary ciliary dyskinesia (PCD) is an inherited condition characterised by repeated upper and lower respiratory tract infections and chronic secretory otitis media. Approximately $50 \%$ patients have disorders of laterality. Morbidity is significant with most patients developing obstructive lung disease

5 Regional Molecular Genetics Laboratory, Great Ormond Street Hospital for Children NHS Foundation Trust, London, UK

6 Division of Genetics and Molecular Medicine, Department of Medical and Molecular Genetics, King's College London School of Medicine, Guy's Hospital, London, UK

7 Division of Molecular and Clinical Medicine, University of Dundee, Dundee, UK 
and bronchiectasis [1-4]. Diagnosis is complex, and may include combinations of suggestive clinical features, low nasal nitric oxide and abnormal ciliary waveform on highspeed videomicroscopy, abnormal ultrastructure defect on electron microscopy (EM) and/or positive genetic tests [5]. There is no uniformly applicable gold standard. Normal ciliary ultrastructure and common PCD ultrastructural defects are shown in Fig. 1.

Ciliary ultrastructural abnormalities can be divided into three broad classes; defects affecting the dynein arms, defects of the microtubules and PCD with normal ultrastructure. The majority of defects occur in the dynein motor proteins which drive ciliary beating, known as the inner and outer dynein arms (IDA, ODA, respectively); these may be caused by gene mutations either leading to failure of synthesis of proteins which form the structural components of the dynein arm proteins or proteins involved in their assembly [1]. Defects of the microtubular arrangement include absence of the central microtubular pair together with transposition of a peripheral doublet (usually caused by defects in radial spoke head genes); and microtubular disorganisation, also often with loss of the inner dynein arm, which usually results from mutations in the 'molecular ruler' and dynein regulatory complex proteins $[6,7] .15-30 \%$ of patients with PCD will have no demonstrable ultrastructural defect on TEM, including those carrying mutations in genes encoding specific ODA (DNAH11) and central pair (HYDIN) proteins [8]. In these patients, confirmation of the diagnosis is made by identification of biallelic mutations in a PCD diseasecausing gene or deemed 'highly likely' based on persistent diagnostic ciliary waveform abnormalities on high-speed videomicroscopy which may be combined with suggestive clinical features and low nasal nitric oxide [9].

Primary ciliary dyskinesia is a heterogeneous condition, with wide variability in clinical status, lung function and outcomes. Previous studies using spirometry, the main tool for accessing disease severity in terms of lung function [specifically forced expiratory volume in $1 \mathrm{~s}\left(\mathrm{FEV}_{1}\right)$ ], have been conflicting [10-12]. A large study recently found spirometry is worse in patients with microtubular defects than in patients with ODA \pm IDA defects, although not all investigators have reported this [13-17].

Lung clearance index (LCI) is derived from multi-breath washout of nitrogen or an exogenous inert gas and is a sensitive measure of distal airway function [18]. The normal range is broadly similar from school age to adulthood. LCI has been shown to be more sensitive to early airways disease than spirometry in cystic fibrosis [19], and is abnormal in patients with PCD $[17,20]$. It may be that this more sensitive parameter is a better tool to access lung function differences in PCD than spirometry.

We hypothesised that LCI would vary between PCD patients with different ultrastructural defects, with the worst results in those with microtubular defects.

\section{Materials and Methods}

\section{Ethics}

The clinical study was approved by NRES Committee South East Coast-Brighton \& Sussex (REC reference: 10/ H1101/69). Genetic analysis was approved by NRES Committee London Bloomsbury for UCL Great Ormond Street Institute of Child Health/Great Ormond Street Hospital (REC reference: 08/H0713/82).

\section{Recruitment}

PCD patients with normal ultrastructure, microtubular defects or outer dynein arm with or without inner dynein $\operatorname{arm}(\mathrm{ODA} \pm \mathrm{IDA})$ were recruited.

Initial recruitment was conducted across the paediatric and adult age range, and 74 paediatric and adult $\mathrm{PCD}$ patients willing to take part were recruited from the respiratory clinics at the Royal Brompton Hospital. However, five patients over 50 years of age originally recruited have been excluded from the main dataset. These patients were
Fig. 1 A diagram of a normal cilium on the left, with a normal ultrastructure, showing microtubular doublets, a central pair, nexin links and radial spokes and inner and outer dynein arms. The electron micrographs on the right show common PCD defects, in $A$, absence of the outer dynein arms, in $B$, absence of inner dynein arms, in $C$, absence of inner dynein arms and microtubular disorganisation and in $D$, absence of both the inner and outer dynein arms

all of white ethnicity, 4/5 had an ODA \pm IDA defect (1 had microtubular defect) and we were unable to recruit equivalent patients of other ethnic origin, or with defects other than $\mathrm{ODA} \pm \mathrm{IDA}$, in this age group. For this reason, they were removed from the main analysis due to introducing an unacceptable risk of bias into the data. Demographics of these removed patients are available in the OLS.

The remaining 69 patients are shown in Table 1. All had undergone detailed evaluation including history and clinical examination including a nasal ciliary brush biopsy which was sent for light microscopic examination and ultrastructural examination by EM.

Inclusion criteria were a positive or highly likely diagnosis of PCD according to current European guidelines [9] based on:

1. A hallmark TEM defect.

2. Biallelic changes in a known PCD gene.

3. Consistent reproducible defects on high-speed video microscopy, coupled with persistently low nasal NO and clinical features of PCD.

The date on which the EM sample was received was used as a surrogate for age at diagnosis (full details of diagnostic process are given below). Patients were stable at time of recruitment with no increase in symptoms in the 2 weeks prior to testing, and no new pathogens grown on cough swab or sputum sample. Note was made if the patient had ever grown Pseudomonas aeruginosa. As PCD is a rare disease, all eligible patients were approached and no statistical sampling method was used.

\section{Lung Function}

Patients performed spirometry (ATS/ERS guidelines [21]), from which forced expiratory volume in $1 \mathrm{~s}\left(\mathrm{FEV}_{1}\right)$ and forced expiratory flow $25-75 \%$ of vital capacity $\left(\mathrm{FEF}_{25-75 \%}\right)$ $z$-scores were calculated using the global lungs initiative (GLI) [22]. At the same visit, after spirometry, they performed multiple breath washout test (MBW) from which LCI was calculated. A sulphur hexafluoride $\left(\mathrm{SF}_{6}\right)$ washout with a photoacoustic gas analyser (Innocor, Innovision, Denmark) was used, with an open breathing circuit, as described previously, with a minimum of 2 runs of acceptable quality, in accordance with ERS/ATS guidelines [18, 20, 23]. Abnormal LCI was defined as $>7.4[18,20]$.

\section{Electron Microscopy}

Samples were fixed in $2.5 \%$ glutaraldehyde in cacodylate buffer, processed for electron microscopy (EM) and defects were quantified [7]. Briefly, cells were washed in sodium cacodylate buffer, post-fixed with $1 \%$ osmium tetroxide and centrifuged in $2 \%$ agar to generate a pellet. Using a series of increasing concentrations of methanol followed by propylene oxide, cells were dehydrated before being embedded in resin. 70-90 nm sections were cut using a Reichert Ultracut-E ultramicrotome and mounted onto copper grids. Heavy metal staining used uranyl acetate and lead citrate. Assessment of the respiratory epithelium and ciliary ultrastructure were made on a transmission electron microscope. Quantification of cells, microtubular arrangement in the axoneme and presence of dynein arms was performed by a clinical electron microscopist. 100-300 cilia were analysed in transverse section and note of ciliary orientation and cell health and appearance of longitudinal ciliary sections was made before a diagnosis of PCD confirmed. Care was taken to assess cilia from a number of healthy cells from locations proximal and distal to the epithelial cell surface.

\section{Genetics}

Mutation data were generated using next-generation sequencing methods, either whole exome sequencing or screening of custom targeted gene panels employing TruSeq (Illumina Inc) and SureSelect (Agilent Technologies) systems and an illumina sequencing system with variant calling performed as previously described [24, 25].

\section{Statistical Methods}

Sample size was opportunistic, since there are no data to inform a power calculation. Non-parametric statistics were used for lung function results. Differences between three and more groups were assessed by Kruskal-Wallis test; and then pairwise between two groups by Mann-Whitney test. Spearman's $r$ was used for correlation.

SPSS (IBM, NY, USA) was used for statistical analysis; graphs were plotted using GraphPad Prism (GraphPad Software Inc, CA, USA).

\section{Results}

\section{Ciliary Ultrastructure}

Demographics are given in Table 1. There was no significant difference between the three groups in age at testing, age at diagnosis, BMI or nasal nitric oxide. Median LCI, FEV ${ }_{1}$ and $\mathrm{FEF}_{25-75 \%}$ were abnormal in all three groups (Fig. 2). The microtubular defects group all had abnormal LCI, but not $\mathrm{FEV}_{1}$ or $\mathrm{FEF}_{25-75 \%}$. Genotyping was available for 55 out of the 69 PCD patients (Table 2).

On non-parametric statistical analysis, LCI was significantly worse in patients with microtubular defects than the other two groups (Table 1; Fig. 2, Kruskal-Wallis 


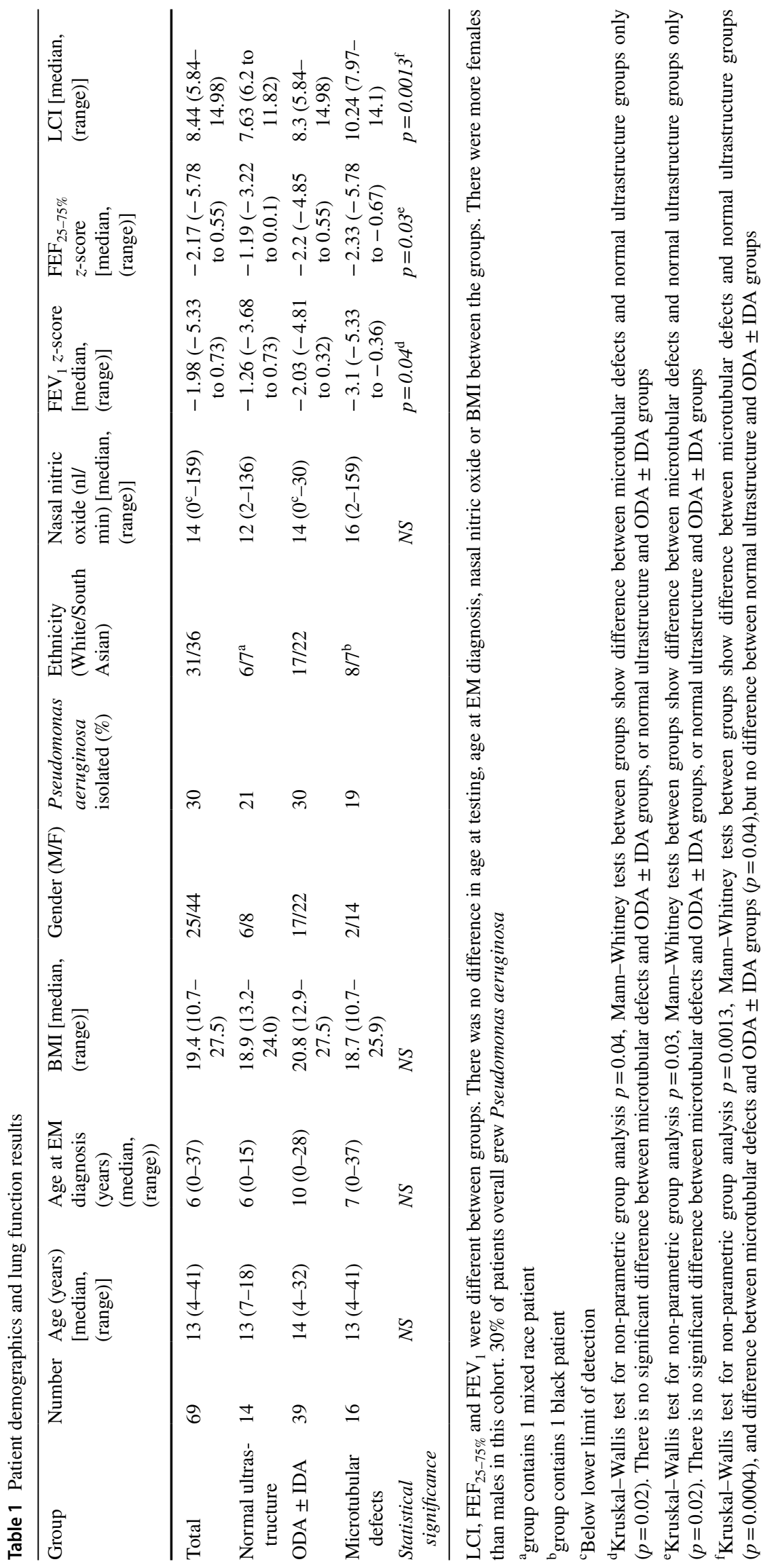


result for three groups $p=0.0013$, pairwise Mann-Whitney result for microtubular defects versus ODA \pm IDA $p=0.004$, and microtubular defects vs normal ultrastructure $p=0.0004)$. $\mathrm{FEV}_{1}$ and $\mathrm{FEF}_{25-75 \%}$ were also significantly worse in patients with microtubular defects compared with the group with normal ultrastructure (Table 1; Fig. 2, Kruskal-Wallis result for three groups $p=0.04$ for $\mathrm{FEV}_{1} z$-score and $p=0.03$ for $\mathrm{FEF}_{25-75 \%}$, pairwise Mann-Whitney result for normal ultrastructure versus microtubular defects $p=0.02$ for both, no other significant differences).

\section{Current Age and Age at Diagnosis}

Current age (at time of testing) was correlated with LCI and FEV $_{1}$ (Fig. 3; age and LCI $p=0.04 r=0.3$, age and FEV 1 $p=0.008, r=-0.3$ ), but not $\mathrm{FEF}_{25-75 \%}$. LCI was not significantly correlated with age at diagnosis, whereas $\mathrm{FEV}_{1}$
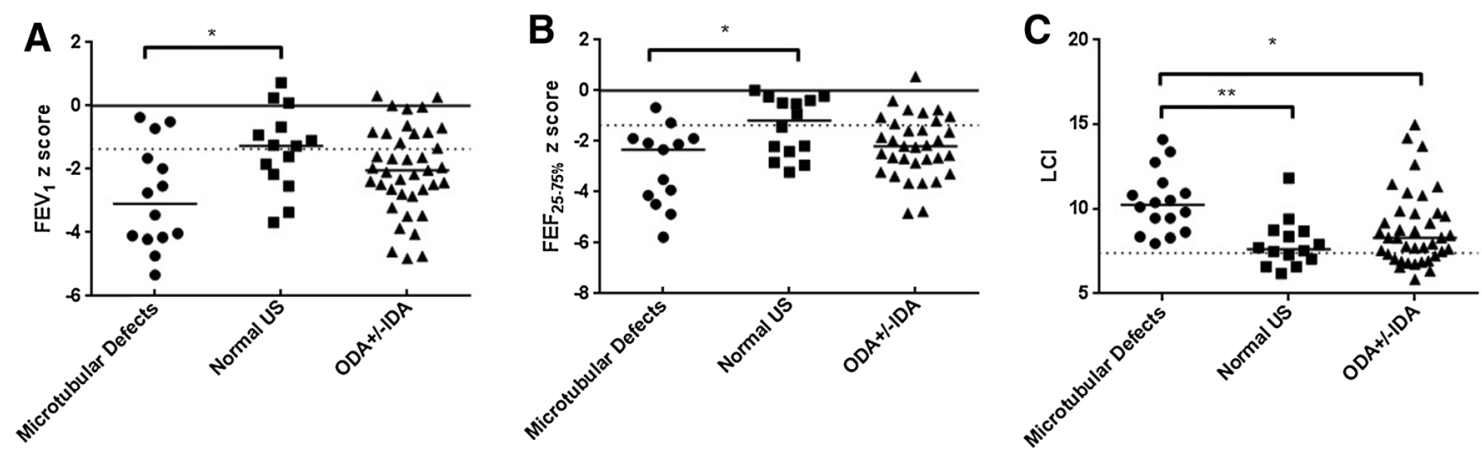

Fig. 2 Differences in lung function tests between groups. Those with normal ultrastructure had the best results, and those with microtubular defects the worst, with ODA \pm IDA intermediate. Panel $\mathrm{A} \mathrm{FEV}_{1} * p=0.02$; Panel B FEF $25-75 \% * p=0.02 ;$ Panel C LCI $* p=0.04 * * p=0.0004$

Table 2 Ultrastructure defect groupings, including genetic results where available

\begin{tabular}{|c|c|c|c|}
\hline \multicolumn{2}{|l|}{ Group } & \multirow{2}{*}{$\begin{array}{l}\text { Number } \\
39 \\
24\end{array}$} & \multirow{2}{*}{$\begin{array}{l}\text { Genetic result } \\
9 \text { DNAH5, } 1 \text { ARMC4, } 1 \text { LRRC6, } 1 \text { DNAAF3, } 2 \text { DNAI1, } 1 \text { pathogenic mutations in } \\
\text { a known PCD gene were not found, } 9 \text { no sample taken }\end{array}$} \\
\hline $\mathrm{ODA} \pm \mathrm{IDA}$ & ODA & & \\
\hline & ODA + IDA & 15 & $\begin{array}{l}5 \text { DNAAF3, } 1 \text { DYX1C1, } 1 \text { ZMYND10, } 1 \text { CCDC103, } 4 \text { LRRC6, } 1 \text { SPAG1, } 2 \text { no } \\
\text { sample taken }\end{array}$ \\
\hline Normal ultrastructure & & 14 & $\begin{array}{l}6 \text { DNAH11, } 3 \text { HYDIN, } 1 \text { CCDC103, } 1 \text { RPGR } \\
1 \text { no sample taken, } 2 \text { pathogenic mutations in a known PCD gene were not found* }\end{array}$ \\
\hline \multirow[t]{2}{*}{ Microtubular defects } & Central complex & $\begin{array}{l}16 \\
4\end{array}$ & 2 RSPH4A, 2 no sample taken \\
\hline & Microtubular defects + IDA & 12 & $\begin{array}{l}5 C C D C 39,4 C C D C 40,1 \text { pathogenic mutations in a known PCD gene were not } \\
\text { found, } 2 \text { no sample taken }\end{array}$ \\
\hline
\end{tabular}

*Three patients with no sample taken for genetics or no gene found showed consistent reproducible abnormalities on high-speed video microscopy

Fig. 3 Relationship between age (a) and age at diagnosis (b) and LCI. Age and LCI correlate significantly $(p=0.0012, r=0.4)$, as does age and $\mathrm{FEV}_{1} z$-score $(p=0.004, r=0.3)$
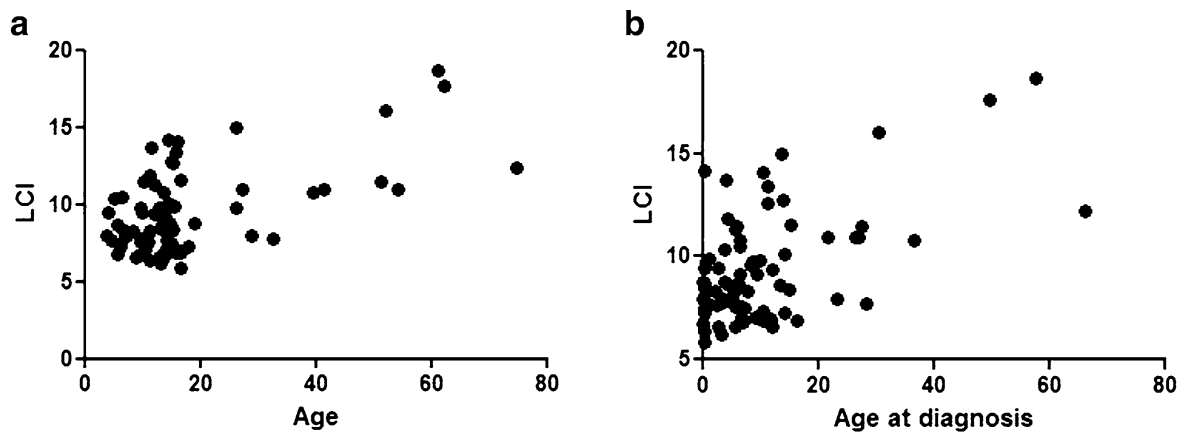
was inversely correlated $(p=0.02, r=-0.4)$. It was possible that younger patients were diagnosed earlier, as awareness of PCD has improved, thus introducing a bias, but there was no change in age at diagnosis over time (results in OLS).

\section{Ethnicity}

Ethnic groups were equally distributed between EM groups (Table 1) and there is no statistically significant difference between $\mathrm{LCI}, \mathrm{FEV}_{1}, \mathrm{FEF}_{25-75 \%}$, nasal nitric oxide, age or age at diagnosis between them.

\section{Ciliary Function}

45 patients had predominantly static cilia on light microscopy, and 21 had predominantly dyskinetic. There was no difference in $\mathrm{LCI}, \mathrm{FEV}_{1}$ and $\mathrm{FEF}_{25-75 \%}$ between these groups (data in OLS). Where beat frequency was measurable with non-static cilia, there was no relationship between beat frequency and lung function (see OLS for full data). There was no relationship between nasal nitric oxide results and lung function (see OLS).

\section{Discussion}

We have shown that PCD patients with microtubular defects have worse LCI compared to groups with normal ultrastructure and dynein arm defects. Microtubular defects were first linked to comparatively worse lung function and decline in previous spirometry-based studies [13, 16], but these differences in LCI are novel, showing the utility of this test as a sensitive tool to investigate lung function differences in PCD. This study supports the hypothesis that there are potential outcome differences between different ultrastructural groups.

Unlike in previous work, there was no significant difference in $\mathrm{FEV}_{1}$ and $\mathrm{FEF}_{25-75 \%}$ between ODA \pm IDA and microtubular defects [13]. This may be because the previous article used percent predicted, whereas we have used $z$-scores. Furthermore, the Wilcoxon signed-rank test for comparison between groups was used, whilst here we used a more stringent approach [16]. However, more data are needed to understand this discrepancy.

The mechanism by which different ultrastructural defects may give rise to differences in lung function in vivo is not clear. Ciliary motility differs between defects which may affect mucociliary transport, but why microtubular defect patients with some ciliary motility (such as the circling pattern seen in transposition defects) should have worse lung function than ODA \pm IDA patients with completely static cilia is not known. Cilia also have a role in cell signalling, and we speculate that this could differ in different ultrastructural groups. In our centre, treatment decisions are based on clinical assessment rather than ultrastructure defect, so it is unlikely any differences arise from treatment differences.

One weakness of this study is the small cohort size. Until very recently, there was no commercially available validated LCI equipment, and measurements were restricted to tertiary centres, and so very large multicentre cohort studies (such as those published in spirometry) were not possible. Recent advances in equipment mean this will change in the coming years, and so establishing the role of this test in these patients is important.

Green et al. [26] found no significant correlation between age or age at diagnosis and lung function in their 2012 PCD cohort. In our cohort we found a correlation between age and LCI and FEV1. This could have been due to a number of factors. Our cohort is larger so may have been better powered to detect this difference, and also Green et al's cohort contained no patients over the age of 18 years, so the effect may be less pronounced in paediatric patients. In this study, we have used age at EM diagnosis as a surrogate measure for age at diagnosis, due to incomplete and varied history of our patients prior to their referral to the PCD centre. This is an acknowledged compromise and may be why no significant association was found.

As many patients do not solely attend our clinic, the microbiological results are incomplete. However, the prevalence of Pseudomonas aeruginosa seen here (30\%) is similar to previous reports; a large multicentre study gives a prevalence of $37 \%$ overall [11], a large adult patient cohort $45 \%$ [16] and another showed a varying prevalence in different calendar years of between 15 and $47 \%$ [27].

In our study, median BMI for all ultrastructure groups was in the healthy range (Table 1). This differs from the previous study [13], where microtubular defects patients had a lower BMI than the other groups. The exact reason for this discrepancy is unclear and may relate to differences in management protocols between centres, but excludes the possibility that low BMI was the cause of poorer lung function results in our microtubular defects patients.

In summary, in PCD, microtubular defects ultrastructure group and older age are associated with worse LCI. We cannot explain this intriguing finding, and more work is needed to address the pathways whereby different ultrastructure affects patient outcomes. In the future, determining the reasons for these differences could open up new treatment pathways, and delineation of high risk groups may allow more targeted intensive treatment to improve prognosis.

Acknowledgements We are very grateful to the families with PCD who participated in this study and to the UK PCD Family Support Group for their support. We would like to thank Mr Winston Banya for his help with statistical analysis, and the NE Thames Regional Genetics Service at Great Ormond Street Hospital for support in 
the genetic analysis. The research is supported by the COST Action 1407 network (BEAT-PCD: Better Evidence to Advance Therapeutic Options for PCD). A.B. was supported by the NIHR Respiratory Disease Biomedical Research Unit at the Royal Brompton and Harefield NHS Foundation Trust and Imperial College London. Work by A.S. is an independent research funded by a postdoctoral research fellowship from the National Institute of Health Research and Health Education England, and the views expressed in this publication are those of the authors and not necessarily those of the NHS, the National Institute of Health Research or the Department of Health. H.M.M. acknowledges support from the National Institute for Health Research Biomedical Research Centre at Great Ormond Street Hospital for Children NHS Foundation Trust and University College London and was supported by Grants from Action Medical Research (GN2101), Newlife Foundation (10-11/15) and the Great Ormond Street Hospital Children's Charity. M.L received funding from Bayer Pharmaceuticals (Berlin) for an investigator lead research grant in lung clearance index.

\section{Compliance with Ethical Standards}

Conflict of interest SI, MD, MRF, EF, JH, KK, SO, AO, MPP, JS, SC, $\mathrm{HMM}, \mathrm{MRL}, \mathrm{CH}, \mathrm{AS}$ and $\mathrm{AB}$ have no conflicts of interest to declare.

Open Access This article is distributed under the terms of the Creative Commons Attribution 4.0 International License (http://creativecommons.org/licenses/by/4.0/), which permits unrestricted use, distribution, and reproduction in any medium, provided you give appropriate credit to the original author(s) and the source, provide a link to the Creative Commons license, and indicate if changes were made.

\section{References}

1. Lucas JS, Burgess A, Mitchison HM, Moya E, Williamson M, Hogg C, Service UKNPCD (2014) Diagnosis and management of primary ciliary dyskinesia. Arch Dis Child 99:850-856

2. Noone PG, Leigh MW, Sannuti A, Minnix SL, Carson JL, Hazucha M, Zariwala MA, Knowles MR (2004) Primary ciliary dyskinesia: diagnostic and phenotypic features. Am J Respir Crit Care Med 169:459-467

3. Bush A, Chodhari R, Collins N, Copeland F, Hall P, Harcourt J, Hariri M, Hogg C, Lucas J, Mitchison HM, O'Callaghan C, Phillips G (2007) Primary ciliary dyskinesia: current state of the art. Arch Dis Child 92:1136-1140

4. Bush A, Hogg C (2012) Primary ciliary dyskinesia: recent advances in epidemiology, diagnosis, management and relationship with the expanding spectrum of ciliopathy. Expert Rev Respir Med 6:663-682

5. Dehlink E, Hogg C, Carr SB, Bush A (2016) Clinical phenotype and current diagnostic criteria for primary ciliary dyskinesia. Expert Rev Respir Med 10:1163-1175

6. Oda T, Yanagisawa H, Kamiya R, Kikkawa M (2014) A molecular ruler determines the repeat length in eukaryotic cilia and flagella. Science 346:857-860

7. Shoemark A, Dixon M, Corrin B, Dewar A (2012) Twenty-year review of quantitative transmission electron microscopy for the diagnosis of primary ciliary dyskinesia. J Clin Pathol 65:267-271

8. Knowles MR, Daniels LA, Davis SD, Zariwala MA, Leigh MW (2013) Primary ciliary dyskinesia. Recent advances in diagnostics, genetics, and characterization of clinical disease. Am J Respir Crit Care Med 188:913-922

9. Lucas JS, Barbato A, Collins SA, Goutaki M, Behan L, Caudri D, Dell S, Eber E, Escudier E, Hirst RA, Hogg C, Jorissen M,
Latzin P, Legendre M, Leigh MW, Midulla F, Nielsen KG, Omran H, Papon J-F, Pohunek P, Redfern B, Rigau D, Rindlisbacher B, Santamaria F, Shoemark A, Snijders D, Tonia T, Titieni A, Walker WT, Werner C et al (2017) European respiratory society guidelines for the diagnosis of primary ciliary dyskinesia. Eur Respir J 49. https://doi.org/10.1183/13993003.01090-2016

10. Marthin JK, Petersen N, Skovgaard LT, Nielsen KG (2010) Lung function in patients with primary ciliary dyskinesia: a cross-sectional and 3-decade longitudinal study. Am J Respir Crit Care Med 181:1262-1268

11. Maglione M, Bush A, Nielsen KG, Hogg C, Montella S, Marthin JK, Di Giorgio A, Santamaria F (2014) Multicenter analysis of body mass index, lung function, and sputum microbiology in primary ciliary dyskinesia. Pediatr Pulmonol 49:1243-1250

12. Ellemunter H, Fuchs SI, Unsinn KM, Freund MC, Waltner-Romen M, Steinkamp G, Gappa M (2010) Sensitivity of lung clearance index and chest computed tomography in early cf lung disease. Respir Med 104:1834-1842

13. Davis SD, Ferkol TW, Rosenfeld M, Lee HS, Dell SD, Sagel SD, Milla C, Zariwala MA, Pittman JE, Shapiro AJ, Carson JL, Krischer JP, Hazucha MJ, Cooper ML, Knowles MR, Leigh MW (2015) Clinical features of childhood primary ciliary dyskinesia by genotype and ultrastructural phenotype. Am J Respir Crit Care Med 191:316-324

14. Ellerman A, Bisgaard H (1997) Longitudinal study of lung function in a cohort of primary ciliary dyskinesia. Eur Respir J 10:2376-2379

15. Vallet C, Escudier E, Roudot-Thoraval F, Blanchon S, Fauroux B, Beydon N, Boule M, Vojtek AM, Amselem S, Clement A, Tamalet A (2013) Primary ciliary dyskinesia presentation in 60 children according to ciliary ultrastructure. Eur J Pediatr 172:1053-1060

16. Shah A, Shoemark A, MacNeill SJ, Bhaludin B, Rogers A, Bilton D, Hansell DM, Wilson R, Loebinger MR (2016) A longitudinal study characterising a large adult primary ciliary dyskinesia population. Eur Respir J 48:441-450

17. Boon M, Vermeulen FL, Gysemans W, Proesmans M, Jorissen M, De Boeck K (2015) Lung structure-function correlation in patients with primary ciliary dyskinesia. Thorax 70:339-345

18. Horsley AR, Gustafsson PM, Macleod KA, Saunders C, Greening AP, Porteous DJ, Davies JC, Cunningham S, Alton EW, Innes JA (2008) Lung clearance index is a sensitive, repeatable and practical measure of airways disease in adults with cystic fibrosis. Thorax 63:135-140

19. Aurora P, Gustafsson P, Bush A, Lindblad A, Oliver C, Wallis CE, Stocks J (2004) Multiple breath inert gas washout as a measure of ventilation distribution in children with cystic fibrosis. Thorax 59:1068-1073

20. Irving SJ, Ives A, Davies G, Donovan J, Edey AJ, Gill SS, Nair A, Saunders C, Wijesekera NT, Alton EW, Hansell D, Hogg C, Davies JC, Bush A (2013) Lung clearance index and high-resolution computed tomography scores in primary ciliary dyskinesia. Am J Respir Crit Care Med 188:545-549

21. Miller MR, Hankinson J, Brusasco V, Burgos F, Casaburi R, Coates A, Crapo R, Enright P, van der Grinten CP, Gustafsson P, Jensen R, Johnson DC, MacIntyre N, McKay R, Navajas D, Pedersen OF, Pellegrino R, Viegi G, Wanger J, Force AT (2005) Standardisation of spirometry. Eur Respir 26:319-338

22. Quanjer PH, Stanojevic S, Cole TJ, Baur X, Hall GL, Culver BH, Enright PL, Hankinson JL, Ip MS, Zheng J, Stocks J, Initiative ERSGLF (2012) Multi-ethnic reference values for spirometry for the 3-95-yr age range: the global lung function 2012 equations. Eur Respir J 40:1324-1343

23. Robinson PD, Latzin P, Verbanck S, Hall GL, Horsley A, Gappa M, Thamrin C, Arets HGM, Aurora P, Fuchs SI, King GG, Lum S, Macleod K, Paiva M, Pillow JJ, Ranganathan S, Ratjen F, Singer F, Sonnappa S, Stocks J, Subbarao P, Thompson BR, 
Gustafsson PM (2013) Consensus statement for inert gas washout measurement using multiple- and singlebreath tests. Eur Respir J 41:507-522

24. Onoufriadis A, Shoemark A, Munye MM, James CT, Schmidts M, Patel M, Rosser EM, Bacchelli C, Beales PL, Scambler PJ, Hart SL, Danke-Roelse JE, Sloper JJ, Hull S, Hogg C, Emes RD, Pals G, Moore AT, Chung EMK, UK10K, Mitchison HM (2014) Combined exome and whole-genome sequencing identifies mutations in ARMC4 as a cause of primary ciliary dyskinesia with defects in the outer dynein arm. J Med Genet 51:61-67

25. Trump N, McTague A, Brittain H, Papandreou A, Meyer E, Ngoh A, Palmer R, Morrogh D, Boustred C, Hurst JA, Jenkins L, Kurian
MA, Scott RH (2016) Improving diagnosis and broadening the phenotypes in early-onset seizure and severe developmental delay disorders through gene panel analysis. J Med Genet 53:310-317

26. Green K, Buchvald FF, Marthin JK, Hanel B, Gustafsson PM, Nielsen KG (2012) Ventilation inhomogeneity in children with primary ciliary dyskinesia. Thorax 67:49-53

27. Alanin MC, Nielsen KG, von Buchwald C, Skov M, Aanaes K, Hoiby N, Johansen HK (2015) A longitudinal study of lung bacterial pathogens in patients with primary ciliary dyskinesia. Clin Microbiol Infect 21:1093.e1-1093.e7 